\title{
Efficacy of micronutrient supplementation on skin aging and seasonal variation: a randomized, placebo-controlled, double-blind study
}

\author{
Ferial Fanian ${ }^{1,2}$ \\ Sophie Mac-Mary ${ }^{3}$ \\ Adeline Jeudy ${ }^{1,2}$ \\ Thomas Lihoreau ${ }^{1,2}$ \\ Rafat Messikh ${ }^{1,2}$ \\ Jean-Paul Ortonne ${ }^{4}$ \\ Jean-Marie Sainthillier ${ }^{3}$ \\ Ahmed Elkhyat ${ }^{1,2}$ \\ Alexandre Guichard ${ }^{1,2}$ \\ Kamran Hejazi Kenari, ${ }^{1,2}$ \\ Philippe Humbert ${ }^{1,2,5,6}$ \\ 'Center for Studies and Research on \\ the Integument (CERT), Department \\ of Dermatology, University Hospital \\ of Besançon, Besançon, France; \\ ${ }^{2}$ Clinical Investigation Center, \\ CIC-BT 506, CHRU Besançon, \\ France; ${ }^{3}$ SKINEXIGENCE, University \\ Hospital of Jean Minjoz, Besançon, \\ France; ${ }^{4}$ Department of Dermatology, \\ University Hospital of L'archet, Nice, \\ France; ${ }^{5}$ University of Franche-Comté, \\ Besançon, France; 'INSERM 1098, \\ Structure Fédérative de Recherche, \\ Besançon, France
}

Correspondence: Philippe Humbert Center for Studies and Research on the Integument (CERT), Department of Dermatology, University Hospital of Besançon, 2 place St Jacques, F-25000 Besançon, France Email philippe.humbert@univ-fcomte.fr
This article was published in the following Dove Press journal:

Clinical Interventions in Aging

14 November 2013

Number of times this article has been viewed

Background: Several studies have confirmed dramatic changes in skin surface parameters during the winter months. Although there are many studies supporting the positive effects of topical treatment, there are no published studies demonstrating the effects of oral supplementation in the prevention of negative skin changes during winter. The purpose of this study was to evaluate the efficacy of an oral micronutrient supplement in preventing the negative effects of winter weather on skin quality using noninvasive biometrologic instruments.

Methods: This study included 80 healthy female volunteers aged 35-55 years with phototype II-IV skin. Randomization was balanced. Two tablets of a micronutrient supplement (Perfectil ${ }^{\circledR}$ Platinum) or placebo were administered once daily for 4 months. The volunteers were examined at baseline, after 4 months, and 6 weeks after termination of treatment (month 5.5). The evaluation included skin microrelief by Visioscan ${ }^{\circledR}$ as the main outcome, and the secondary outcomes were results on standard macrophotography, skin tension by Reviscometer ${ }^{\circledR}$, skin high-frequency ultrasound, and self-assessment.

Results: For all pseudoroughness and microrelief indicators, there was a significant increase from baseline to month 4 in the placebo group $(P<0.05)$ but no change in the active group. Descriptive statistics for the mean minimum, mean maximum, and minimum to maximum ratio on the nonexposed study zone showed a significant and dramatic difference between baseline and month 4 and between baseline and month $5.5(P<0.05)$ in the active group, indicating decreasing anisotropy of the skin. High-frequency ultrasound on the exposed study zone revealed that skin thickness was significantly decreased in the placebo group during winter but was stable in the treated group $(P<0.01)$. The photography scaling and self-assessment questionnaire revealed no significant changes in either group.

Conclusion: These results indicate that the skin is prone to seasonal changes during winter, particularly in exposed areas. The data also indicate that oral supplementation can be a safe treatment, with no serious side effects, and may prevent or even eliminate the negative effects of winter on the skin.

Keywords: oral supplementation, skin, elasticity, relief, high-frequency ultrasound, Reviscometer $^{\circledR}$, Visioscan ${ }^{\circledR}$, nutraceuticals, winter variation

\section{Introduction}

It has been appreciated for decades that aging is a consequence of both genetic and environmental influences. Among the environmental factors, solar ultraviolet radiation is most important for extrinsic skin aging, a process also known as photoaging. ${ }^{1}$ Vitamins and micronutrients have been used in systemic and topical photoprotection. Dietary photoprotection through administration of carotenoids, tocopherol, and vitamin $\mathrm{C}$ in foods or supplements has been successfully used to 
prevent ultraviolet-induced erythema. ${ }^{2}$ Even in normal adults, a dry and cold winter season has a marked influence on the condition of the skin, and affects the face more than the forearm. Clinical observation reveals that approximately one third of children show visible dry skin changes in winter. ${ }^{3}$ Although hydration and barrier function in the stratum corneum may behave independently in some skin conditions, such as senile xerosis and fresh scars, they show concomitant changes in scaly inflammatory skin lesions. Even individuals with normal skin show subclinical changes in their facial skin when exposed to the dryness and coldness of winter, which can be demonstrated biophysically as decreased hydration and deteriorating barrier function of the stratum corneum. ${ }^{4}$ Wrinkling and sagging, two macroscopic features of aging skin, have been found to show no seasonal influence. Such findings are not surprising for two major reasons. First, skin aging is a rather slow process, more easily seen over years and decades than months. Second, structural changes, such as sagging and wrinkling, clearly originate in alterations in the dermis, which is a tissue with slow turnover. ${ }^{4}$ Therefore, these microscopic changes, year after year, may lead to the macroscopic and visible signs of skin aging.

Today, nutritional supplements with cosmetic aims have a broad spectrum of ingredients, including traditional antioxidants like vitamins $\mathrm{E}$ and $\mathrm{C}$ and also new-generation nutrients like polyphenols. ${ }^{5,6}$ Different names are used to identify these supplements, such as endocosmesis and nutricosmeceuticals. ${ }^{7}$ To overcome skin problems, Rona et al suggested that a complete approach to dermocosmetic conditions could involve correct association of a topical treatment with an oral one on the basis of their synergy, thereby fighting both symptoms and their causes. ${ }^{7}$ Women are more susceptible to environmental factors for two reasons: skin thickness in women is significantly less than that in men ${ }^{8-11}$ and the tissue dielectric constant is $13 \%$ higher in male skin than in female skin, and is a reliable marker for local tissue water. ${ }^{11}$ All of this evidence suggests that skin dryness increases during winter, exposed areas are more susceptible to seasonal changes, and female skin is more prone to these changes.

To the authors' knowledge, there has been no published research concentrating on the preventative effects of oral supplementation on the negative seasonal effects on skin. The current study was designed to evaluate the effects of a multinutrient supplement on season-related skin surface changes and on more deep parameters of the skin after 4 months of oral treatment during winter and 6 weeks after stopping supplementation via noninvasive instruments.

\section{Subjects and methods}

This study was a randomized, single-center, double-blind, placebo-controlled comparative study of 80 healthy female volunteers (Figure 1) aged 35-55 years and with Fitzpatrick phototype II-IV skin. All subjects had significant photoaging of the face based on photographic appearance, ${ }^{12}$ without sun or ultraviolet exposure 48 hours before the first day or during the study. The subjects agreed to use only basic moisturizing products for daily skin care during the study. They were not participating in any other research during the trial period. Consistent with the principles laid down in the Declaration of Helsinki, all subjects signed their informed consent before recruitment. The protocol was approved from an ethical point of view by the scientific committee of the Center of Clinical Investigations (INSERM CBT506), University Hospital of Besançon, Besançon, France. The study was conducted at the Department of Dermatology, St Jacques University Hospital, Besançon, France.

All subjects underwent clinical examination and noninvasive bioengineering measurements (French Health Ministry authorization $09023 \mathrm{M}$ and $09023 \mathrm{~S}$ for the conduct of clinical studies with drugs, medical devices, and cosmetic products). The study was done in winter (October to April) with a mean local temperature of $-4^{\circ} \mathrm{C}$ in January and $+18.7^{\circ} \mathrm{C}$ in April (Table 1). Exclusion criteria were pregnancy, lactation, use of oral nutritional complements, and/or vitamin supplementation in the 2 months before the study, use of cosmetics containing antiaging ingredients (eg, vitamin C, vitamin A, retinaldehyde, or similar), hypersensivity to one or more ingredient(s) of the study product, serious acute or chronic illness, skin disease, and systemic or local treatment, such as topical or oral corticosteroids or diuretics with the potential to interfere with measurement of the study parameters. Two tablets of a micronutrient supplement (Perfectil ${ }^{\circledR}$ Platinum, Vitabiotics Ltd, London, UK, Table 2) were administered once daily with the main meal for 4 months. The volunteers were examined at T0 (before treatment), T4 (4 months, ie, 122 days, end of treatment) and T5.5 (6 weeks after termination of treatment). Randomization was balanced according to two blocks and eight layers on the basis of age group, skin dryness, and hormone replacement therapy.

All subjects were instructed to wash their face and arms on the evening preceding the examination days (T0, T4, and T5.5) and not to apply anything to their face or arms (including water, soap, shower gel, cream, or make-up) until after examination.

Measurements were done at a regulated temperature of $20^{\circ} \mathrm{C} \pm 2^{\circ} \mathrm{C}$ and a regulated humidity of $55 \% \pm 5 \% .^{13}$ 


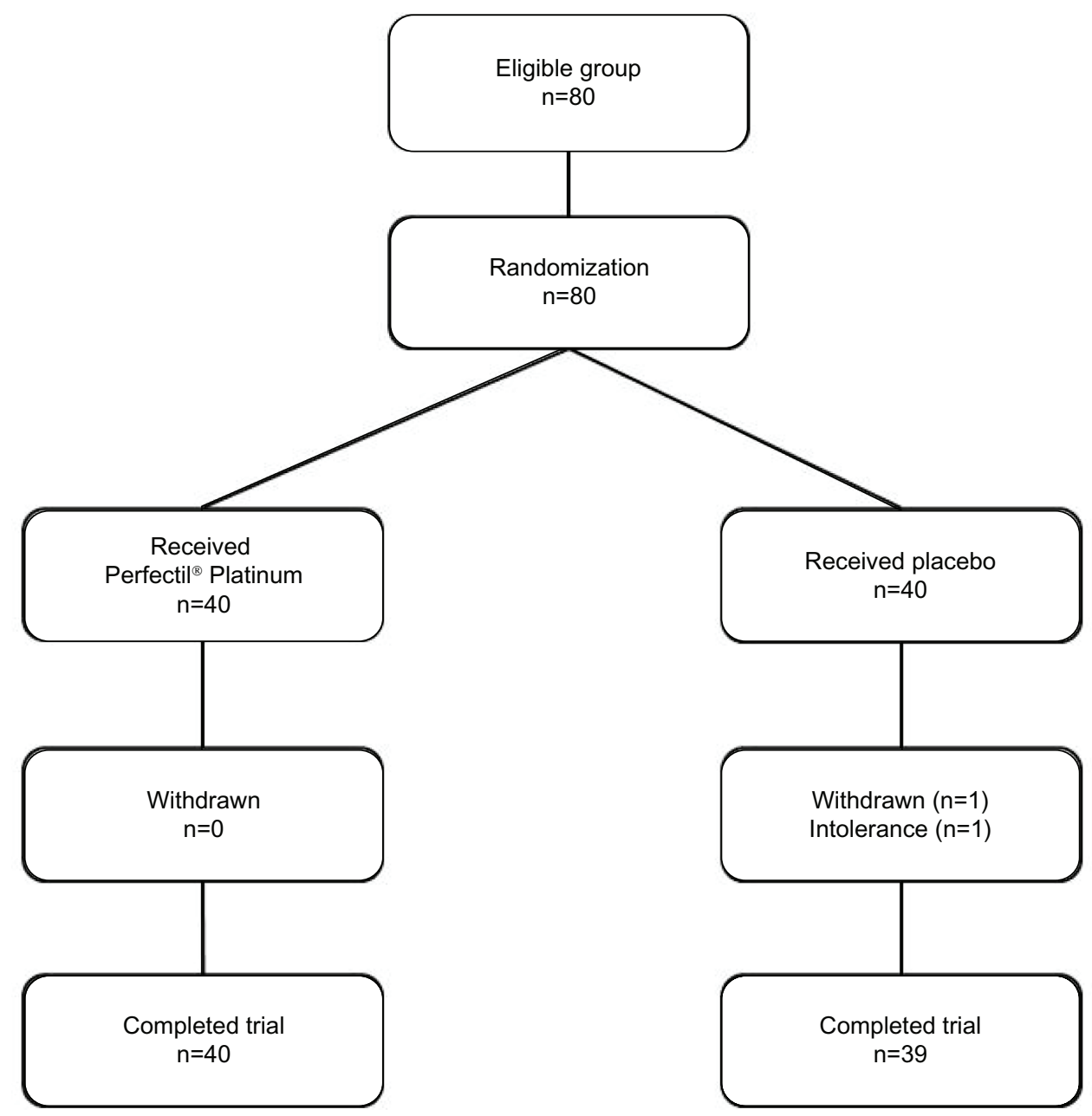

Figure I Flow chart describing trial progress.

Note: Perfecti ${ }^{\circledR}$ Platinum; Vitabiotics Ltd, London, UK.

The volunteers rested quietly for at least 15 minutes in stable environmental conditions prior to assessment. The skin was not subject to any strain or stress. All measures were performed in the supine position. The skin areas measured included the face (using digital photography and skin relief), anterior side of the forearm (nonexposed zone), and back of the hand (exposed zone) using skin viscoelasticity and

Table I Mean minimum and maximum of weather temperature during the study period

\begin{tabular}{lll}
\hline Months & Mean minimum ${ }^{\circ} \mathbf{C}$ & Mean maximum ${ }^{\circ} \mathbf{C}$ \\
\hline $\mathbf{2 0 0 8}$ & & \\
October & +7.4 & +16.4 \\
November & -0.5 & +5.6 \\
December & -0.9 & +3.8 \\
$\mathbf{2 0 0 9}$ & & \\
January & -4.0 & +2.6 \\
February & -3.6 & +2.5 \\
March & +1.5 & +6.5 \\
April & +6.7 & +18.7 \\
\hline
\end{tabular}

high-frequency ultrasound imaging. Measurements were recorded using a flexible transparent plastic mask. This allowed measurements to be done in exactly the same place at each visit (Thermocell-Test ${ }^{\circledR}$ professional kit, Monaderm, Monte Carlo, Monaco).

\section{Evaluation methods}

\section{Standardized macrophotography}

Standardized photographs of the face were taken with a D70 digital camera and an objective AF Micro-Nikkor $60 \mathrm{~mm}$ lens (Nikon Corporation, Tokyo, Japan). The photographs were taken in the sitting position, under normal and polarized light for the face, both front and profile, with the same camera positioning, the same light conditions, and at the same distance to the skin $(1 \mathrm{~m})$ at each visit using a stereotactic facial system (Canfield Scientific Inc, Fairfield, NJ, USA) including a metallic platform (Figure 2). The photoevaluation was performed by a panel of experienced professionals according to a six-grade photographic scale ${ }^{12}$ (devised by F Hoffmann-La 
Table 2 Nutritional information for Perfectil ${ }^{\circledR}$ Platinum

\begin{tabular}{|c|c|c|}
\hline Ingredient & Mean per two tablets & $\%$ RDA \\
\hline Bio marine collagen (Cartidea ${ }^{\mathrm{TM}}$ ) & $200 \mathrm{mg}$ & - \\
\hline $\begin{array}{l}\text { Grape seed extract } \\
\text { (95\% proanthocyanidins) }\end{array}$ & $15 \mathrm{mg}$ & - \\
\hline $\begin{array}{l}\text { Pine bark extract } \\
\text { ( } 95 \% \text { proanthocyanidins) }\end{array}$ & $8 \mathrm{mg}$ & - \\
\hline Green tea extract & $20 \mathrm{mg}$ & - \\
\hline Lycopene extract $5 \%$ & $10 \mathrm{mg}$ & - \\
\hline Blackcurrant seed oil & $50 \mathrm{mg}$ & - \\
\hline Alpha lipoic acid & $40 \mathrm{mg}$ & - \\
\hline Coenzyme QI0 & $5 \mathrm{mg}$ & - \\
\hline Betacarotene & $4 \mathrm{mg}$ & - \\
\hline Vitamin D3 (as D3 IU) & $12.5 \mu g$ & 250 \\
\hline Vitamin E (natural source) & $50 \mathrm{mg}$ & 417 \\
\hline Vitamin C & $90 \mathrm{mg}$ & 113 \\
\hline Thiamin (vitamin BI) & $8 \mathrm{mg}$ & 727 \\
\hline Riboflavin (vitamin B2) & $4 \mathrm{mg}$ & 286 \\
\hline Niacin (vitamin B3) & $18 \mathrm{mg}$ & 113 \\
\hline Vitamin B6 & $10 \mathrm{mg}$ & 714 \\
\hline Folacin (folic acid) & $400 \mu g$ & 200 \\
\hline Vitamin BI2 & $9 \mu \mathrm{g}$ & 360 \\
\hline Biotin & $150 \mu g$ & 300 \\
\hline Pantothenic acid & $40 \mathrm{mg}$ & 667 \\
\hline Magnesium & $100 \mathrm{mg}$ & 27 \\
\hline Iron & $12 \mathrm{mg}$ & 86 \\
\hline Zinc & $15 \mathrm{mg}$ & 150 \\
\hline Copper & $\mathrm{I}, 000 \mu \mathrm{g}$ & 100 \\
\hline Manganese & $0.5 \mathrm{mg}$ & 25 \\
\hline Selenium (yeast-free) & $100 \mu g$ & 182 \\
\hline Chromium & $50 \mu g$ & 125 \\
\hline lodine (from purified sea kelp extract) & $200 \mu g$ & 133 \\
\hline Silicon & $50 \mathrm{mg}$ & - \\
\hline L-cystine & $20 \mathrm{mg}$ & - \\
\hline
\end{tabular}

Note: Perfectil ${ }^{\circledR}$ Platinum; Vitabiotics Ltd, London, UK.

Abbreviations: RDA, recommended daily allowance; IU, International Units.

Roche Ltd, Basel, Switzerland) rating the overall severity of facial photodamage as grade 1 to 6 (mild, mild/moderate, moderate, moderate/severe, severe, very severe).

\section{Skin relief}

Skin relief (fine lines and wrinkles) was evaluated using a Visioscan ${ }^{\circledR}$ VC 98 device (Courage and Khazaka, Cologne, Germany, Figure 3)..$^{13,14}$ The Visioscan VC 98 features a blackand-white high-performance digital camera that takes pictures of the skin surface under standardized homogenous ring-shaped ultraviolet A illumination (340-400 nm, peak $375 \mathrm{~nm}$ ). Each $640 \times 480$ pixel picture was analyzed using dedicated software (VisioScan 2000) and parameters representing pseudoroughness (R1 [Rt], R2 [Rm], and R3 [Rz], indicators of deep wrinkles) and microrelief (R4 [Rp] and R5 [Ra], indicators of microrelief).

$\mathrm{Rz}$, or circular roughness, is the arithmetic average of five measurements of the distance between the highest and lowest value, referred to as reference length 1 , on a selected line.

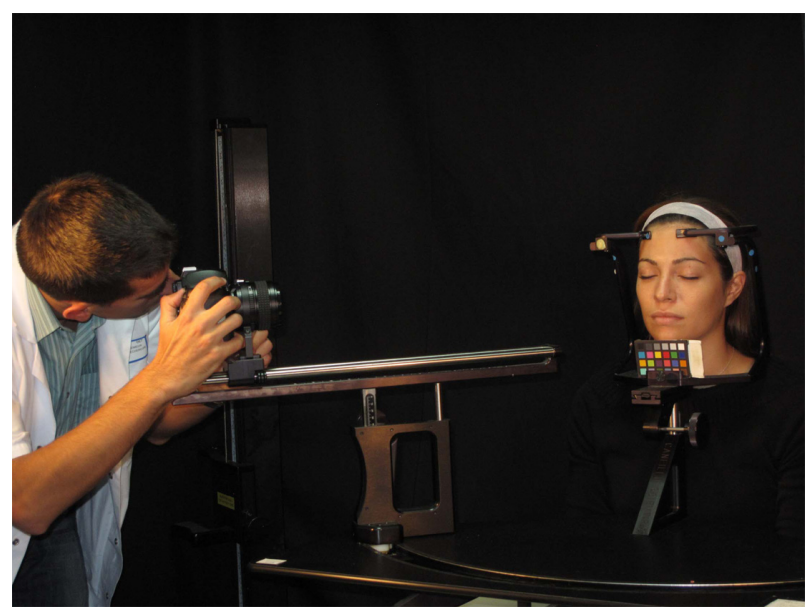

Figure 2 Patient positioning for standard photography.

Lines can be arranged horizontally, vertically, or circularly. The advantage of circularly arranged lines is that any influence from the direction of the wrinkles is compensated. ${ }^{15,16}$

The SELS (surface evaluation of living skin) method is based on a graphic depiction of living skin under special illumination, and electronic processing and evaluation of this image was carried out according to two clinical parameters:

- skin roughness (Ser), the roughness parameter, which calculates the gray levels above the threshold in comparison with the entire image (reflects skin "asperity")

- wrinkles (Sew), identifies aging including wrinkles, and is calculated from the proportion of horizontal and vertical wrinkles. ${ }^{13}$

\section{Skin viscoelasticity}

A sensitive biometrologic device (Reviscometer ${ }^{\circledR}$ RVM 600, ${ }^{17}$ Courage and Khazaka) was used to measure skin viscoelasticity. This device measures the propagation velocity of acoustic shockwaves. For this purpose, two sensors are applied to the skin surface (Figure 4). The mean resonance running time over the four axes was calculated, as well as values at $0^{\circ}$ to $180^{\circ}$ and $90^{\circ}$ to $270^{\circ}$ separately. Four measurements were done for each zone (inner forearm and back of the hand) in each four directions and mean values were calculated. ${ }^{18}$

\section{Skin thickness and density}

An ultrasonic wave (frequency $20 \mathrm{MHz}$ ) was applied via an echographic device (Dermcup ${ }^{\circledR}$, Atys Medicale, Soucieu en Jarrest, France) on the surface of the skin by means of a suitable probe head. Three images were taken from each measurement zone (inner forearm and back of the hand). For each image, three measurements of skin thickness were 

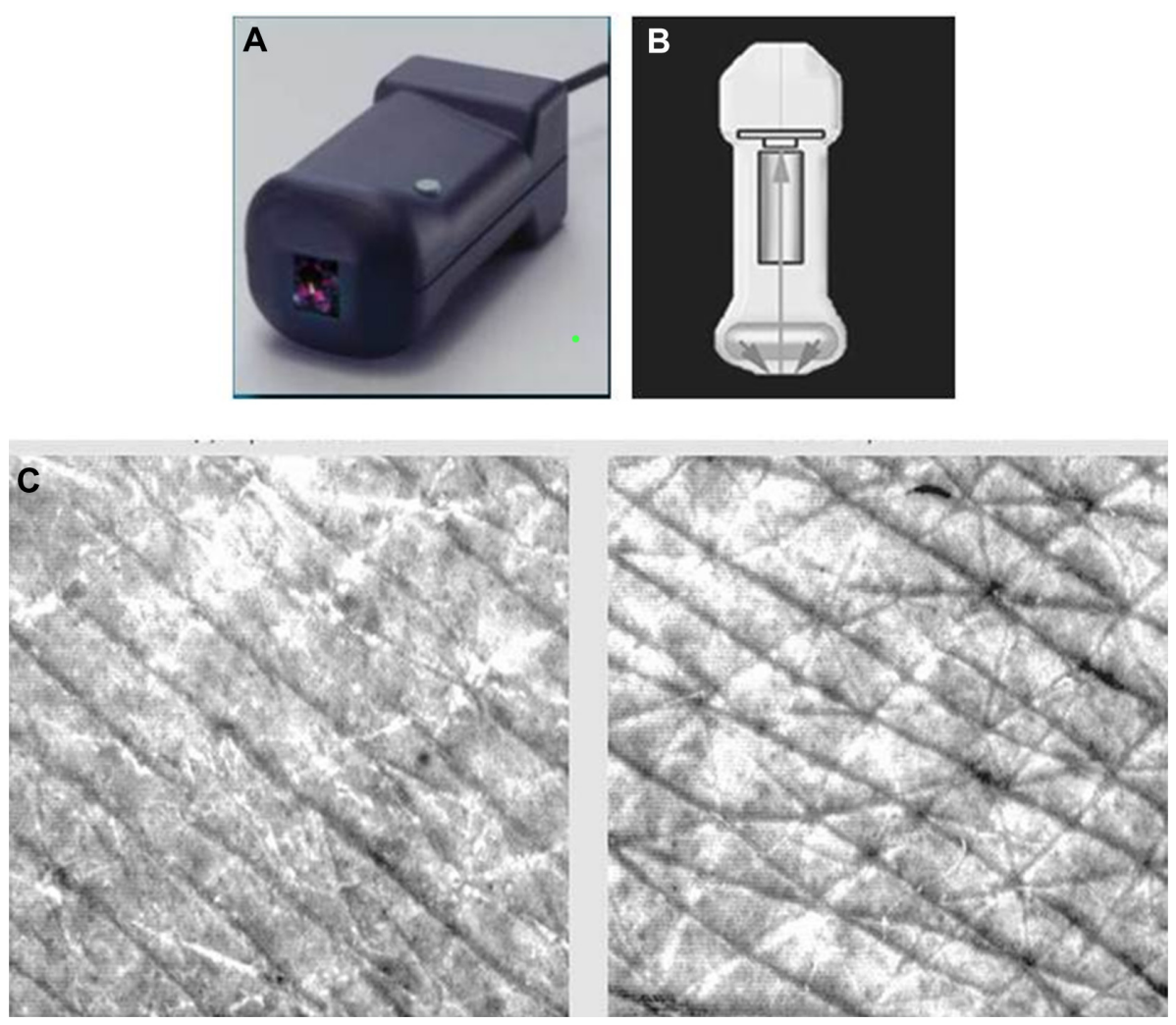

Figure 3 Visioscan ${ }^{\circledast}$ VC 98

Notes: (A-B) The camera features a high resolution black and white video sensor and a ring shaped UV-A light source (proven to present no hazard to normal human skin) for uniform illumination of the skin. (C) Wrinkles appear dark in the image; scaliness is shown in bright pixels. The software calculates a variety of parameters like roughness indices, skin topography volume, anisotropy and corner density. Visioscan ${ }^{\circledR}$ VC 98; Courage and Khazaka, Cologne, Germany.
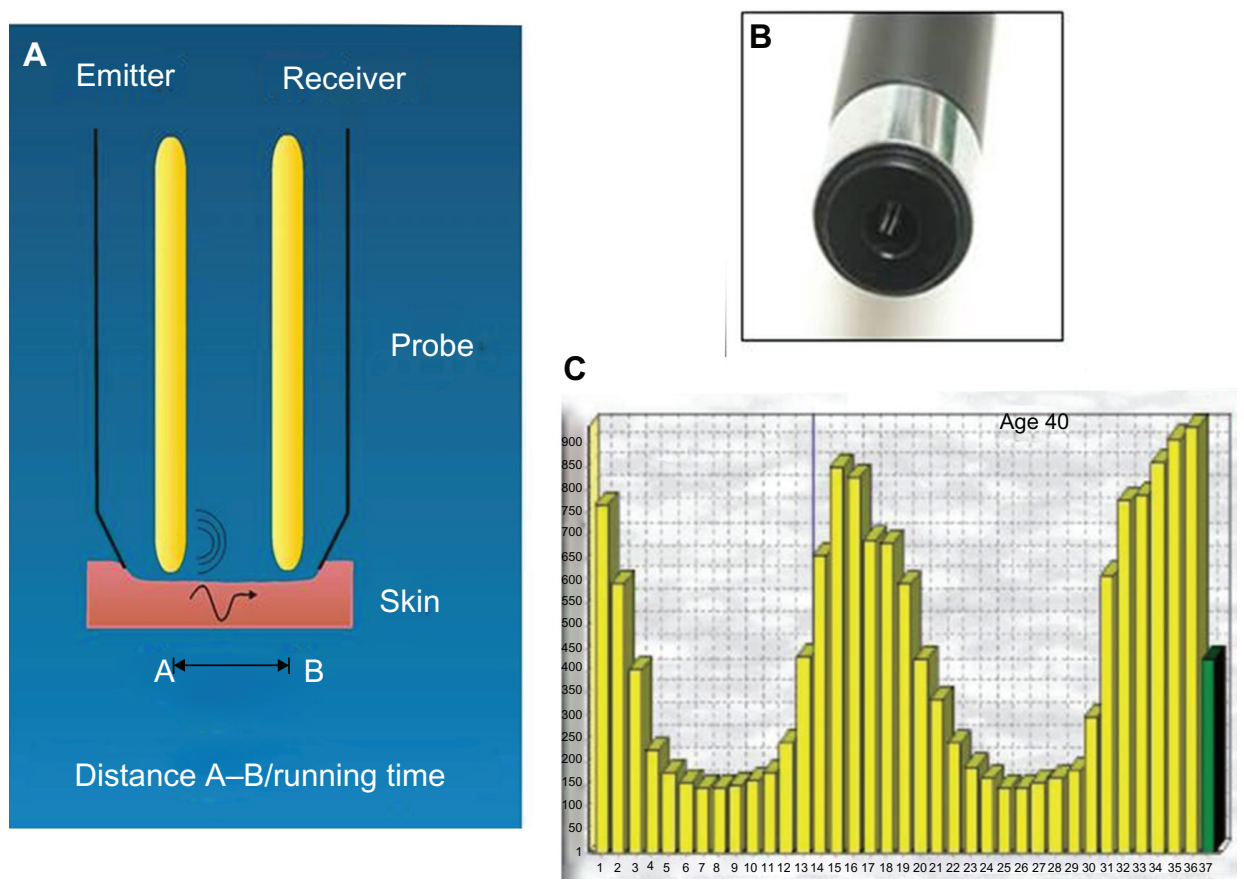

Figure 4 Reviscometer ${ }^{\circledast}$ RVM 600.

Notes: (A) Mechanism: two sensors are applied on the skin surface. One sensor is emitting the acoustic wave $\mathbf{A}$; the other is the receiver $\mathbf{B}$. The software measures the propagation velocity of acoustic shockwaves. (B) Scaled head positioned in $0-180^{\circ}, 45-225^{\circ}, 90-270^{\circ}$, and $135-315^{\circ}$-axis, fixed with a double sided adhesive ring. (C) The software calculates the mean value of the RRT (resonance running time) parameter over 4 axes. Reviscometer ${ }^{\circledR}$ RVM 600; Courage and Khazaka, Cologne, Germany. 
conducted (three values per zone per volunteer) and mean values were calculated. The data were analyzed by proprietary software (Skinexigence, Besançon, France). The thickness was calculated from a region of interest determined directly on the image. The density was defined as the mean region of interest luminance.

\section{Subject self-evaluation}

The subjects answered the self-evaluation questionnaire at the T4 visit.

\section{Statistical analysis}

The statistical analysis was conducted using Statistica ${ }^{\circledR}$ version 6.0 (Statsoft, Tulsa, OK, USA) and Instat GraphPad ${ }^{\circledR}$ version 3.0 (Graphpad Software Inc, San Diego, CA, USA) software. The analyses were based on the intention-to-treat population that comprised all subjects included in the study. Statistical significance was set at 5\% (double-sided) and at $5 \%-10 \%$ for trends. Descriptive statistics were reported for each parameter, ie, mean standard deviation, minimum, maximum, and median, quartiles for quantitative data, and percentages for qualitative data. Quantitative variables were tested by analysis of variance (if normal distribution was ensured, or Friedman test if not normally distributed). The effect of time (at T0, T4, and T5.5) was investigated using these tests. If the time effect was statistically significant, the analysis was completed by a test for multiple comparisons (Dunn's test).

\section{Results}

The primary outcome was evaluation of cutaneous fine lines, skin microrelief, and wrinkles on the face. The secondary outcomes were skin thickness and density, subject selfassessment, illustrative macrophotography, and tolerance.

\section{Study population}

Eighty healthy Caucasian female volunteers aged 36-55 years (mean $46 \pm 6$ years; mean for active group 46.6 years; mean for placebo group 46.4 years) were enrolled (Table 3 ). One subject terminated the study prematurely because of an intolerance reaction to the placebo tablet (so results for the placebo group are based on 39 subjects). Mean body mass index in the study population was in the normal range, ie, 20-25 (mean body mass index in the active group was $22.7 \pm 2.1$ and in placebo group was $23.4 \pm 4.3$ ). Thirty percent of women in the active group and $35 \%$ of those in the placebo group were menopausal. In the active group, three subjects $(7.5 \%)$ had been receiving hormone replacement
Table 3 Subject demographic data

\begin{tabular}{|c|c|c|}
\hline \multirow[t]{2}{*}{ Parameter } & \multicolumn{2}{|l|}{ Test group } \\
\hline & $\begin{array}{l}\text { Active group } \\
(n=40)\end{array}$ & $\begin{array}{l}\text { Placebo group } \\
(n=39)\end{array}$ \\
\hline Average age, years & $46.6 \pm 5.4$ & $46.4 \pm 5.9$ \\
\hline Body mass index $\left(\mathrm{kg} / \mathrm{m}^{2}\right)$ & $22.7 \pm 2.1$ & $23.4 \pm 4.3$ \\
\hline Menopause & 14 (35\%) & $12(30 \%)$ \\
\hline Hormonal replacement therapy & $3(7.5 \%)$ & $3(7.65 \%)$ \\
\hline Dry skin & $17(43 \%)$ & $18(45 \%)$ \\
\hline Smoking history & $7(18 \%)$ & $10(25 \%)$ \\
\hline Pack-years & $7.5 \pm 5.6$ & $7.5 \pm 5.1$ \\
\hline Mininum & 1.5 & 0.3 \\
\hline Maximum & 15 & 15 \\
\hline
\end{tabular}

therapy for 2, 8, and 4 months, while three subjects (7.65\%) in the placebo group had been receiving hormone replacement therapy for 3, 5, and 16 years. Forty-three percent of the active group and $45 \%$ of the placebo group had dry skin according to subject self-reporting. No differences were observed in terms of smoking status between the two groups ( $7.5 \pm 5.6$ pack-years in the active group and $7.5 \pm 5.1$ pack-years in the placebo group). No serious side effects were observed.

\section{Primary outcome of skin relief}

For all pseudoroughness and microrelief indicators like Rt (R1), Rm (R2), Rz (R3), and Ra, there was a significant negative increase from $\mathrm{T} 0$ to $\mathrm{T} 4$ in the placebo group (for $\mathrm{Rt}$ [R1] between T4 and T5.5 [ $P<0.01]$, for Rm [R2] between $\mathrm{T} 4$ and $\mathrm{T} 5.5[P<0.01]$, and for $\mathrm{Rz}[\mathrm{R} 3]$ between $\mathrm{T} 0$ and T5.5 $[P<0.05])$ while there was no adverse change in the active group (Table 4 and Figure 5). This effect was also observable for $\mathrm{Rp}(\mathrm{R} 4)$, but was not statistically significant. No significant effects were found for SELS parameters (Ser and Sew, Tables 4 and 5).

\section{Secondary efficacy outcomes Viscoelasticity}

No difference was observed in mean resonance running times (multidirectional) between the two groups for the nonexposed (forearm) or exposed (dorsum of the hand) areas. On the nonexposed area (forearm), the most important differences were observed on the $45^{\circ}$ and $135^{\circ}$ axes. The data showed that the resonance running time at $45^{\circ}$ was significantly decreased in the active group by $13 \%$ from T0 to T5.5 $(P<0.05$, Table 4$)$. Descriptive statistics of the mean minimum, mean maximum, and minimum to maximum ratio showed a nonsignificant difference between T0 and T4 $(P=0.0579)$ and between T0 and T5.5 $(P=0.0512)$ in the active group (Table 4$)$. 
Table 4 Results of instrumental assessments at T0, T4, and T5.5 in the active and placebo groups including statistical significance

\begin{tabular}{|c|c|c|c|c|c|c|}
\hline \multirow[t]{2}{*}{ Group } & \multicolumn{3}{|c|}{ Perfectil ${ }^{\circledR}$ Platinum } & \multicolumn{3}{|l|}{ Placebo } \\
\hline & Forearm & Hand & Face & Forearm & Hand & Face \\
\hline \multicolumn{7}{|c|}{ Roughness, Rt (RI) } \\
\hline T0 & - & - & 0.303 & - & - & 0.303 \\
\hline $\mathrm{T} 4$ & - & - & $0.312^{\mathrm{a}}$ & - & - & $0.32 I^{\mathrm{c}}$ \\
\hline T5.5 & - & - & $0.295^{\mathrm{a}}$ & - & - & $0.290^{c}$ \\
\hline \multicolumn{7}{|c|}{ Roughness, Rm (R2) } \\
\hline T0 & - & - & 0.256 & - & - & 0.254 \\
\hline T4 & - & - & $0.257^{\mathrm{a}}$ & - & - & $0.262^{c}$ \\
\hline T5.5 & - & - & $0.243^{\mathrm{a}}$ & - & - & $0.240^{c}$ \\
\hline \multicolumn{7}{|c|}{ Circular roughness, $\mathbf{R z}(\mathbf{R} 3)$} \\
\hline T0 & - & - & 0.201 & - & - & $0.199^{\mathrm{b}}$ \\
\hline $\mathrm{T} 4$ & - & - & $0.200^{\mathrm{a}}$ & - & - & $0.206^{\mathrm{b}}$ \\
\hline T5.5 & - & - & $0.189^{a}$ & - & - & $0.187^{b}$ \\
\hline \multicolumn{7}{|c|}{ Microrelief indicator, Ra } \\
\hline T0 & - & - & 0.0443 & - & - & 0.0445 \\
\hline T4 & - & - & $0.046 \mathrm{I}^{\mathrm{a}}$ & - & - & 0.0490 \\
\hline T5.5 & - & - & $0.0439^{\mathrm{a}}$ & - & - & 0.0430 \\
\hline \multicolumn{7}{|c|}{ Microrelief indicator, Rp } \\
\hline T0 & - & - & 0.157 & - & - & 0.158 \\
\hline T4 & - & - & $0.154^{\mathrm{a}}$ & - & - & $0.159^{\mathrm{a}}$ \\
\hline T5.5 & - & - & $0.15 I^{\mathrm{a}}$ & - & - & $0150^{\mathrm{a}}$ \\
\hline \multicolumn{7}{|c|}{ SELS parameter, Ser (skin microroughness) } \\
\hline T0 & - & - & 0.27 & - & - & 0.25 \\
\hline $\mathrm{T} 4$ & - & - & $0.30^{\mathrm{a}}$ & - & - & $0.29^{a}$ \\
\hline T5.5 & - & - & $0.25^{\mathrm{a}}$ & - & - & $0.28^{\mathrm{a}}$ \\
\hline \multicolumn{7}{|c|}{ SELS parameter, Sew (wrinkles) } \\
\hline T0 & - & - & 132.14 & - & - & 127.31 \\
\hline $\mathrm{T} 4$ & - & - & $|20.7|^{a}$ & - & - & 117.23 \\
\hline T5.5 & - & - & $128.45^{\mathrm{a}}$ & - & - & 123.90 \\
\hline \multicolumn{7}{|c|}{ Viscoelasticity } \\
\hline T0 & $220.2^{\mathrm{c}, *}$ & $\mid 58.3^{\mathrm{c}, *}$ & - & $229.4^{\mathrm{d}, *}$ & $|70 .|^{\mathrm{c}, *}$ & - \\
\hline $\mathrm{T} 4$ & 214.4 & | 47.4 & - & $2 \mid 4 . I^{d, *}$ & 156.3 & - \\
\hline T5.5 & $201.9^{c, *}$ & |38.9c,* & - & $204.5^{\text {d,* }}$ & $149.0^{c, *}$ & - \\
\hline \multicolumn{7}{|c|}{ Skin thickness } \\
\hline TO & 1.09 & 1.10 & - & 1.09 & 1.13 & - \\
\hline $\mathrm{T} 4$ & $1.16^{6}$ & 1.07 & - & $1.13^{b}$ & $1.09^{c}$ & - \\
\hline T5.5 & $1.15^{b}$ & 1.07 & - & $1.13^{\mathrm{a}}$ & $1.11^{\mathrm{c}}$ & - \\
\hline \multicolumn{7}{|c|}{ Skin density } \\
\hline T0 & 97.56 & 76.30 & - & 99.77 & 75.26 & - \\
\hline $\mathrm{T} 4$ & $120.87^{b}$ & $107.08^{\mathrm{b}}$ & - & $122.27^{\mathrm{b}}$ & $106.13^{b}$ & - \\
\hline T5.5 & $130.50^{b}$ & $107.33^{b}$ & - & $125.8 \mathrm{I}^{\mathrm{b}}$ & $108.54^{b}$ & - \\
\hline \multicolumn{7}{|c|}{ Photographic scoring } \\
\hline T0 & - & - & 3.0 & - & - & 3.1 \\
\hline $\mathrm{T} 4$ & - & - & $3.0^{\mathrm{a}}$ & - & - & $3.1^{a}$ \\
\hline T5.5 & - & - & $3.0^{\mathrm{a}}$ & - & - & $3 . I^{a}$ \\
\hline
\end{tabular}

Notes: alf $P \geq 0.05$, the result is considered nonsignificant; bif $0.01<P<0.05$ the result is considered significant; 'if $0.00 \mathrm{I}<P<0.0 \mathrm{I}$ the result is considered very significant; dif $P<0.001$ the result is considered extremely significant; *nonparametric analysis of variance (Friedman's test) did not identify a difference, but Dunn's test confirmed results; values are expressed in surface units, calculated by Visioscan VC 98 software; values are expressed in contrast units, calculated by Visioscan VC 98 software; values are expressed in roughness units, calculated by Visioscan VC 98 software; TO, baseline; T4, after 4 months of treatment; T5.5, 6 weeks after termination of treatment. Perfectil ${ }^{\circledast}$ Platinum; Vitabiotics Ltd, London, UK. Visioscan ${ }^{\circledast}$ VC 98 . Courage and Khazaka, Cologne, Germany.

On the exposed area (dorsum of the hand), the most significant differences in the active group were observed at $90^{\circ}$ between $\mathrm{T} 0$ and T5.5. The nonparametric Friedman test did not show any time effect for mean resonance running time either in the active group or in the placebo group, while Dunn's test highlighted a significant difference between T0 and T5.5 in both the active group $(P<0.01)$ and the placebo group $(P<0.01$, Table 5).

Descriptive statistics of the mean minimum, mean maximum, and minimum to maximum ratio showed a significant and dramatic difference between T0 and T4 $(P=0.0001)$ and between T0 and T5.5 $(P=0.0008)$ in the active group (Table 5), which was not significant in the placebo group $(P=0.072)$.

\section{Skin thickness and density on ultrasound}

On the unexposed study area (forearm), skin thickness and density was significantly increased in both groups $(P<0.05)$ but more important changes between $\mathrm{T} 0$ and $\mathrm{T} 4$ were observed in the active group (not statistically significant). In the active group, skin thickness was decreased after stopping supplementation $(P<0.05)$, but no changes were observed for the placebo group $(P>0.05$, Table 4$)$. Skin density continued to increase in both groups between T4 and T5.5, but was more pronounced in the active group (albeit not significantly so). In contrast, on the exposed study area (back of the hand), skin thickness was decreased significantly in the placebo group between T0 and T4 (winter time) in both groups which was significant only in the placebo group $(P<0.01$, Dunn's test). The skin density was improved significantly in both groups $(P<0.05)$ but was not treatment-related.

\section{Photographic evaluation}

The mean grade evaluation for the active group was 3.0 and for placebo group was 3.1 at T0, which did not change during the study.

\section{Subject self-assessment}

The self-assessment questionnaire revealed a positive increase in elasticity and firmness and a decrease in roughness and dryness in the active group; however this did not reach statistical significance.

\section{Discussion}

Previous studies have shown that winter seasonal changes could have negative effects on the structural components of skin, eg, free fatty acids, linoleic acid, some saturated fatty acids, oleic acid, stratum corneum lipids, ceramide 1 linoleate, and ceramide 1 oleate, as well as biometrologic parameters, including skin water content, transepidermal water loss, and skin sebum. ${ }^{19-22}$ There are also other reports confirming higher transepidermal water loss values accompanied by smaller sizes of corneocytes in winter, reflecting 
The vertical bars represent the confidence interval of 0.95

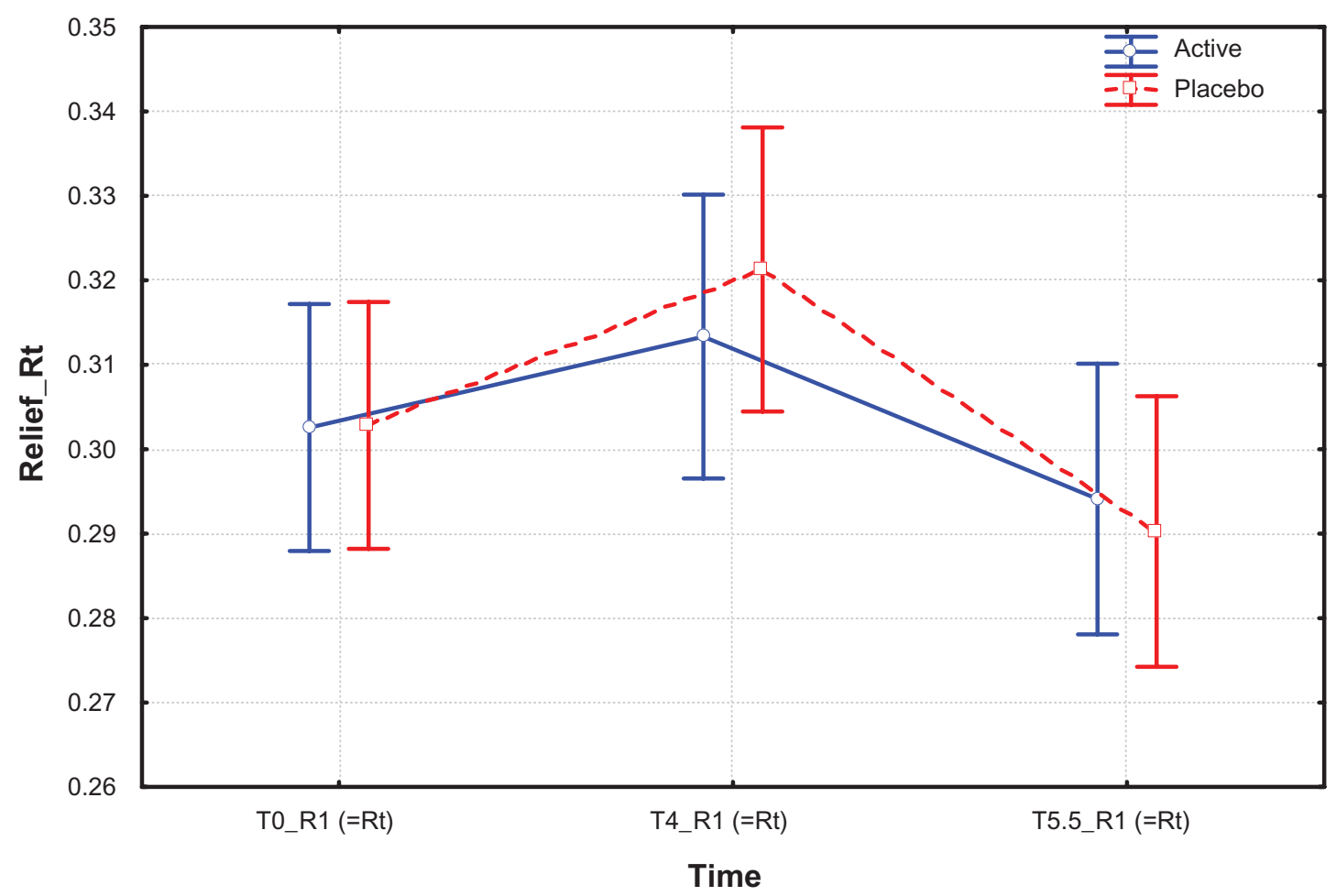

Figure 5 Skin relief, pseudoroughness Rt (RI) values at T0, T4, and T5.5 months in active treatment and placebo groups.

Notes: T0, baseline; T4, after 4 months of treatment; T5.5, 6 weeks after termination of treatment.

more rapid turnover of the epidermis, probably due to irritation caused by the dry and cold winter environment. ${ }^{23} \mathrm{On}$ the other hand, low humidity can stimulate epidermal DNA synthesis as a hyperproliferative reaction to barrier disruption..$^{23}$ There is limited information on skin elasticity changes during the winter months. All these reports indicate a need to provide an intervention to prevent the negative effects of winter time.

There are many studies confirming the positive effects of topical treatments ${ }^{22,24}$ but no published study, to the authors' knowledge, on the preventive effects of oral supplementation for total body skin. Nevertheless, an increasing number of in vitro and in vivo studies support the view that nutritional

Table 5 Minimum/maximum ratio for nonexposed and exposed study zones at T0, T4, and T5.5 months in active $\left(\right.$ Perfectil ${ }^{\circledR}$ Platinum) and placebo groups, indicating anisotropia

\begin{tabular}{llllllll}
\hline & \multicolumn{3}{l}{ Perfecti $^{\circledR}$ Platinum } & & \multicolumn{3}{l}{ Placebo } \\
\cline { 2 - 3 } & T0 & T4 & T5.5 & & T0 & T4 & T5.5 \\
\hline Forearm & 0.50 & $0.52^{\mathrm{a}}$ & $0.56^{\mathrm{a}}$ & & 0.55 & 0.55 & 0.59 \\
Hand & 0.56 & $0.86^{\mathrm{b}}$ & $0.69^{\mathrm{b}}$ & & 0.58 & $0.58^{\mathrm{a}}$ & $0.64^{\mathrm{a}}$ \\
\hline
\end{tabular}

Notes: alf $P \geq 0.05$ the result is considered nonsignificant; bif $P<0.00$ I the result is considered extremely significant; T0, baseline; T4, after 4 months of treatment; T5.5, 6 weeks after termination of treatment. Perfecti ${ }^{\otimes}$ Platinum; Vitabiotics Ltd, London, UK. supplements can improve skin quality. ${ }^{5-7,15,25-27}$ Our study protocol was the same as other studies in this field, ${ }^{16}$ but the study population ( $\mathrm{n}=80)$ was larger and designed to investigate the protective effects of oral supplementation over the winter months. ${ }^{15,27}$ As observed in previous research, the macroscopic clinical signs of wrinkles and firmness did not show any particular change over a 6-month period, ${ }^{4}$ because wrinkle formation and sagging of the facial skin are long-term cumulative effects and would not be particularly affected by 4 months of treatment, so there may be a need for more prolonged studies in this regard.

Consistent with earlier reports, ${ }^{15,16}$ we observed that one of the best skin relief parameters for studying skin surface changes was circular roughness; however, in the present study, other pseudoroughness indicators, eg, Rt and Rm, also showed significant augmentation in the placebo group during winter, which were not shown in the active group and can describe the protective effects of the nutritional supplement in the active group $(P<0.05)$. Considering the seasonal period during which this study was conducted, this difference can be considered as a protective effect of the active supplement against skin dryness during winter. These results were also confirmed by microrelief indicators (Ra and Rp, Table 4). In 
a similar study, Béguin ${ }^{15}$ used only circular roughness (Rz), and his findings confirmed the efficacy of supplementation in decreasing this parameter. No significant effects were seen for the SELS parameters, ie, Ser and Sew, which is consistent with the earlier findings of Pena Ferreira et al. ${ }^{13}$ Therefore, these parameters are not recommended for use in future short-term studies.

In 2007, Paye et al reported that the Reviscometer may be a very sensitive instrument for detecting changes in the mechanical properties of skin, but care must be taken in choosing the directions of measurement for achieving the highest sensitivity. ${ }^{17}$ Data from their study showed that a decrease in resonance running time could also be associated with a dry/dehydrated skin, so interpretation of such data requires a good understanding of the hydration status of the skin surface. ${ }^{17}$

An interesting finding in our study was the effectiveness of the supplement in decreasing skin anisotropy. As shown in Figure 6, the minimum to maximum ratio of the nonexposed study area increased (albeit not significantly) in the active group from T0 to T4 (winter months) indicating modified skin anisotropy, but this was not seen in the placebo group. Subsequently, after stopping the supplement, the minimum to maximum ratio increased progressively, probably reflecting the positive effect of spring time. On the other hand, on the exposed skin area, which is more prone to seasonal changes, the protective effect of the oral supplement was highly significant in the active group (Figure 7). No study seems to have been published regarding the use of the Reviscometer for evaluating the effect of nutritional supplementation on skin.

The results obtained for skin thickness and density by high-frequency ultrasound revealed interesting effects of environmental factors in winter. As shown in Table 4, skin thickness on the nonexposed area (forearm) was not significantly different between the groups, but the thickness of the exposed area (dorsum of the hand) decreased significantly $(P<0.01$, Dunn's test $)$ in the placebo group between T0 and T4 (winter), but not significantly in the active group. This result confirms the protective effects of nutritional supplementation on skin thickness in exposed areas and is in line with previous research. ${ }^{15}$ On the other hand, our results show a decrease in skin thickness after stopping supplementation $(P<0.05)$. These findings

The vertical bars represent the confidence interval of 0.95

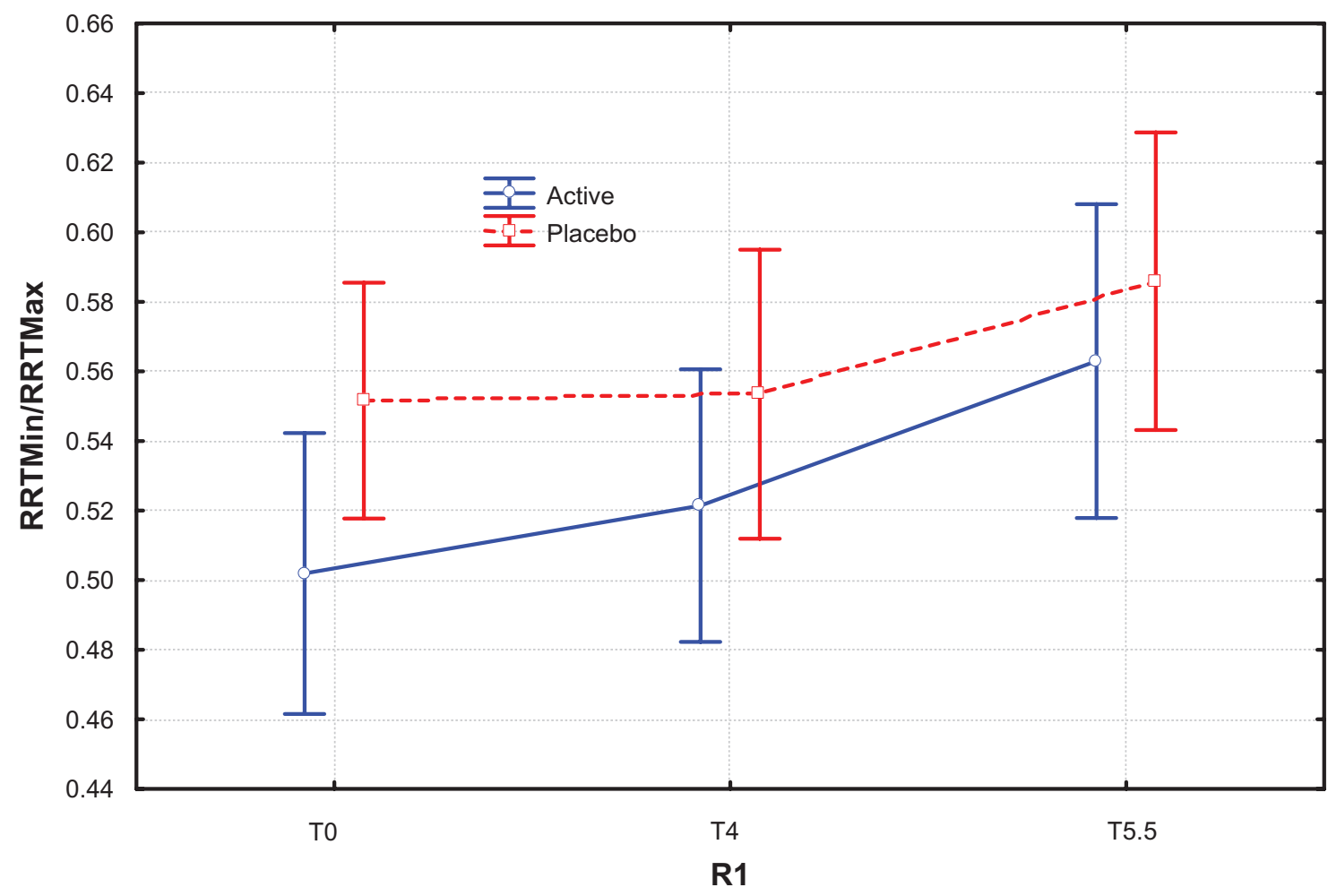

Figure 6 Minimum/maximum resonance running time ratio for nonexposed study zone at T0, T4, and T5.5 months in active treatment (Perfectil ${ }^{\circledR}$ Platinum) and placebo groups. The ratio is increased at T4 for the active group, indicating that anisotropia had decreased by this time $(P=0.0579)$.

Notes: T0, baseline; T4, after 4 months of treatment; T5.5, 6 weeks after termination of treatment. Perfectil ${ }^{\circledR}$ Platinum; Vitabiotics Ltd, London, UK.

Abbreviation: RRT, resonance running time. 


\section{The vertical bars represent the confidence interval of 0.95}

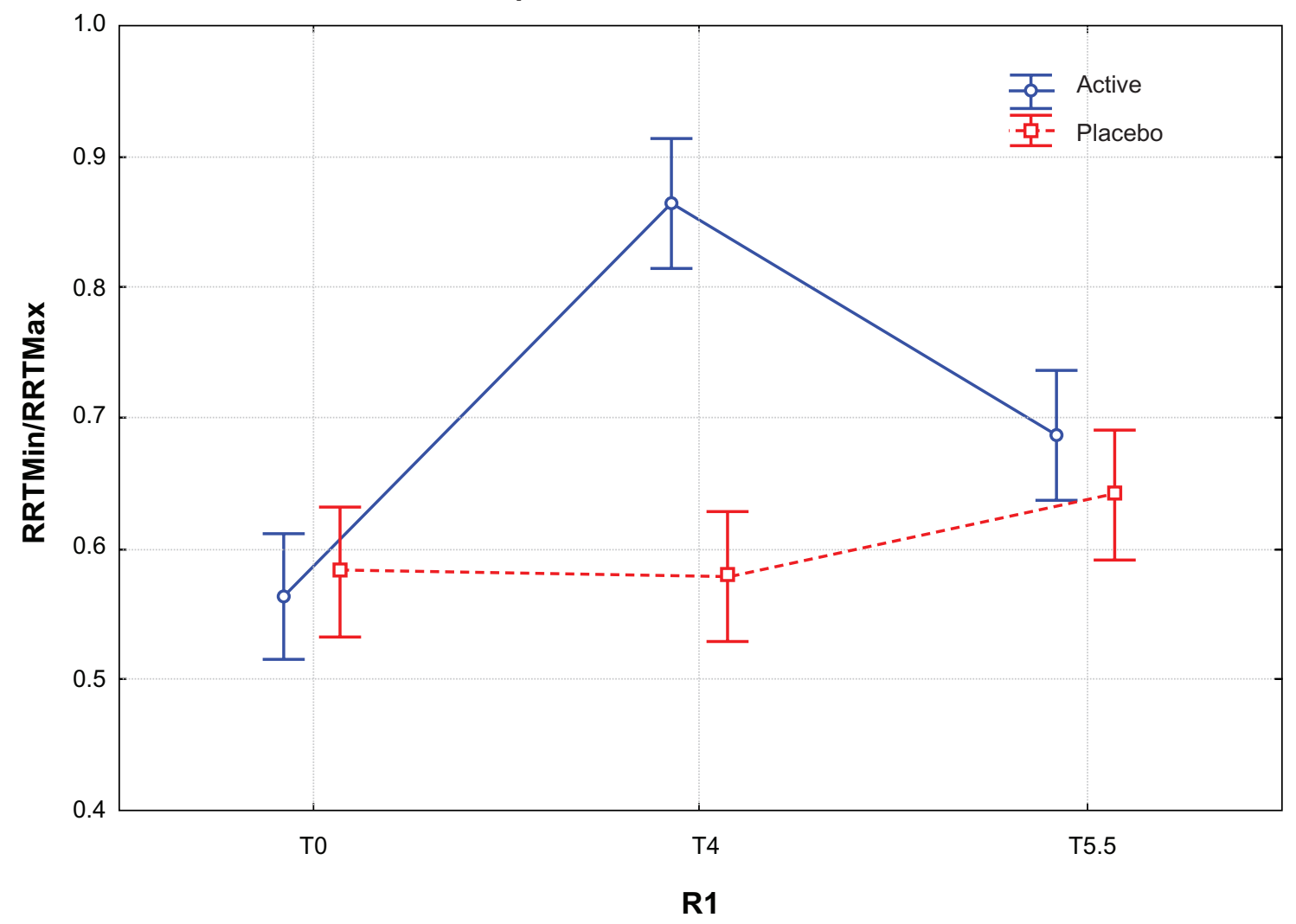

Figure 7 Minimum/maximum resonance running time ratio for exposed study zone at T0, T4, and T5.5 months in active treatment (Perfectil ${ }^{\circledR}$ Platinum) and placebo groups. The ratio is increased at T4 for the active group, indicating that anisotropia had decreased by this time $(P=0.0579)$.

Notes: T0, baseline; T4, after 4 months of treatment; T5.5, 6 weeks after termination of treatment. Perfectil ${ }^{\circledR}$ Platinum; Vitabiotics Ltd, London, UK.

Abbreviation: RRT, resonance running time.

highlight the importance of continuing treatment, at least for longer than the duration of this study. Defining the minimum treatment duration needs further longer-term studies.

Although the photographs in the report by Béguin ${ }^{15}$ indicate significant visible improvement, we did not find any significant macroscopic changes. The photographic scale we used has a limited benefit for this type of study because clinical signs of skin aging, including facial wrinkles and sagging, would not show any appreciable change over such a short period of time. However, the observed protection of the skin, if repeated over a number of winter seasons, could lead to long-term macroscopic clinical improvement.

Subject self-assessment did not reveal any significant difference between the two groups, probably because of the known high placebo effect in such studies. In addition, as with macroscopic changes, we may need to do a longerterm study in order to allow enough time for such changes to become apparent.

\section{Conclusion}

The results of this study indicate that the skin is prone to being affected by seasonal changes, particularly in exposed areas. Our data also confirm that oral supplementation with specific nutrients is safe and may prevent or even eliminate the negative effects of the winter months on skin. Among the instruments used in this trial, Visioscan and high-frequency ultrasound were considered to be more sensitive because they recorded even small changes. The Reviscometer could be a very sensitive instrument if skin surface hydration is considered adequate. During winter time, the most important and also statistically significant changes has been observed in the exposed area as the most prone zone to seasonal changes.

\section{Acknowledgment}

Patient consent was obtained for publication of Figure 2. This research was made possible by the help and support of the patients, technicians, and research engineers at our center, especially Mrs Celine Thiebaud for her enthusiasm in carrying out the sensitive and accurate measures. 


\section{Disclosure}

The authors report no conflicts of interest in this work.

\section{References}

1. Krutmann J. Skin aging. In: Krutmann J, Humbert P, editors. Nutrition for Healthy Skin. Berlin, Germany: Springer-Verlag; 2011.

2. Sies H, Stahl W. Nutritional protection against skin damage from sunlight. Аппи Rev Nutr. 2004;24:173-200.

3. Akutsu N, Ooguri M, Onodera T, et al. Functional characteristics of the skin surface of children approaching puberty: age and seasonal influences. Acta Derm Venereol. 2009;89(1):21-27.

4. Qiu H, Long X, Ye JC, et al. Influence of season on some skin properties: winter vs summer, as experienced by 354 Shanghaiese women of various ages. Int J Cosmet Sci. 2011;33(4):377-383.

5. Janjua R, Munoz C, Gorell E, et al. A two-year, double-blind, randomized placebo-controlled trial of oral green tea polyphenols on the longterm clinical and histologic appearance of photoaging skin. Dermatol Surg. 2009;35(7):1057-1065.

6. Oyetakinwhite P, Tribout H, Baron E. Protective mechanisms of green tea polyphenols in skin. Oxid Med Cell Longev. 2012;2012:560682.

7. Rona C, Berardesca E. Aging skin and food supplements: the myth and the truth. Clin Dermatol. 2008;26(6):641-647.

8. Sans N, Faruch M, Chiavassa-Gandois H, De Ribes CLC, Paul C, Railhac JJ. High-resolution magnetic resonance imaging in study of the skin: normal patterns. Eur J Radiol. 2011;80(2):e176-e181.

9. Crisan D, Lupsor M, Boca A, Crisan M, Badea R. Ultrasonographic assessment of skin structure according to age. Indian J Dermatol Venereol Leprol. 2012;78(4):519.

10. Shuster S, Black MM, McVitie E. The influence of age and sex on skin thickness, skin collagen and density. Br J Dermatol. 1975;93(6): 639-643.

11. Mayrovitz HN, Carson S, Luis M. Male-female differences in forearm skin tissue dielectric constant. Clin Physiol Funct Imaging. 2010;30(5): $328-332$.

12. Larnier C, Ortonne JP, Venot A, et al. Evaluation of cutaneous photodamage using a photographic scale. Br J Dermatol. 1994;130(2): 167-173.

13. Pena Ferreira MR, Costa PC, Bahia FM. Efficacy of anti-wrinkle products in skin surface appearance: a comparative study using non-invasive methods. Skin Res Technol. 2010;16(4):444-449.

14. Yuan C, Wang X, Tan Y, Yang L, Lin Y, Wu P. Effects of sunscreen on human skin's ultraviolet radiation tolerance. J Cosmet Dermatol. 2010;9(4):297-301.

15. Béguin A. A novel micronutrient supplement in skin aging: a randomized placebo-controlled double-blind study. J Cosmet Dermatol. 2005;4(4):277-284.
16. Manuskiatti W, Schwindt DA, Maibach HI. Influence of age, anatomic site and race on skin roughness and scaliness. Dermatology. 1998;196(4):401-407.

17. Paye M, Mac-Mary S, Elkhyat A, Tarrit C, Mermet P, Humbert PH. Use of the Reviscometer for measuring cosmetics-induced skin surface effects. Skin Res Technol. 2007;13(4):343-349.

18. Agache P, Humbert P. Mechanical behavior assessement. In: Agache P, Humbert P, editors. Measuring the Skin. Berlin, Germany: SpringerVerlag; 2004.

19. Conti A, Rogers J, Verdejo P, Harding CR, Rawlings AV. Seasonal influences on stratum corneum ceramide 1 fatty acids and the influence of topical essential fatty acids. Int J Cosmet Sci. 1996;18(1):1-12.

20. Akimoto K, Yoshikawa N, Higaki Y, Kawashima M, Imokawa G. Quantitative analysis of stratum corneum lipids in xerosis and asteatotic eczema. J Dermatol. 1993;20(1):1-6.

21. Rogers J, Harding C, Mayo A, Banks J, Rawlings A. Stratum corneum lipids: the effect of ageing and the seasons. Arch Dermatol Res. 1996;288(12):765-770.

22. Kikuchi K, Kobayashi H, Hirao T, Ito A, Takahashi H, Tagami H. Improvement of mild inflammatory changes of the facial skin induced by winter environment with daily applications of a moisturizing cream. A half-side test of biophysical skin parameters, cytokine expression pattern and the formation of cornified envelope. Dermatology. 2003;207(3):269-275.

23. Denda M, Sato J, Tsuchiya T, Elias PM, Feingold KR. Low humidity stimulates epidermal DNA synthesis and amplifies the hyperproliferative response to barrier disruption: implication for seasonal exacerbations of inflammatory dermatoses. J Invest Dermatol. 1998;111(5): 873-878.

24. Kikuchi K, Tagami H; Japanese Cosmetic Scientist Task Force for Skin Care of Atopic Dermatitis. Noninvasive biophysical assessments of the efficacy of a moisturizing cosmetic cream base for patients with atopic dermatitis during different seasons. Br J Dermatol. 2008;158(5): 969-978.

25. Lacroix S, Bouez C, Vidal S, et al. Supplementation with a complex of active nutrients improved dermal and epidermal characteristics in skin equivalents generated from fibroblasts from young or aged donors. Biogerontology. 2007;8(2):97-109.

26. Takahashi M, Morita T, Fukuoka T, Imura T, Kitamoto D. Glycolipid biosurfactants, mannosylerythritol lipids, show antioxidant and protective effects against $\mathrm{H}_{2} \mathrm{O}_{2}$-induced oxidative stress in cultured human skin fibroblasts. J Oleo Sci. 2012;61(8):457-464.

27. Udompataikul M, Sripiroj P, Palungwachira P. An oral nutraceutical containing antioxidants, minerals and glycosaminoglycans improves skin roughness and fine wrinkles. Int J Cosmet Sci. 2009;31(6):427-435.
Clinical Interventions in Aging

\section{Publish your work in this journal}

Clinical Interventions in Aging is an international, peer-reviewed journal focusing on evidence-based reports on the value or lack thereof of treatments intended to prevent or delay the onset of maladaptive correlates of aging in human beings. This journal is indexed on PubMed Central, MedLine, the American Chemical Society's 'Chemical Abstracts

\section{Dovepress}

Service' (CAS), Scopus and the Elsevier Bibliographic databases. The manuscript management system is completely online and includes a very quick and fair peer-review system, which is all easy to use. Visit $\mathrm{http} / / / \mathrm{www}$.dovepress.com/testimonials.php to read real quotes from published authors. 